\title{
Natural inhibitors of fibrinolysis
}

\section{COLLEN}

From the Centre for Thrombosis and Vascular Research, Department of Medical Research, University of Leuven, Belgium

There are two main types of inhibitors of fibrinolysis: those which inhibit plasmin (plasmin inhibitors or antiplasmins) and those which inhibit the activation of plasminogen (anti-activators). Many substances derived from biological fluids, tissues, plants, or micro-organisms inhibit fibrinolysis. Some active site titrants of serine proteases are potent inhibitors of fibrinolytic enzymes and certain amino-acids such as lysine, 6-aminohexanoic acid, or tranexamic acid inhibit the digestion of fibrin. This review will deal mainly with the natural inhibitors of fibrinolysis occurring in human blood. The properties of the other inhibitors are reviewed elsewhere. ${ }^{1}$

\section{Inhibitors of plasmin occurring in human blood}

Human plasma exerts a very important inhibitory action on plasmin. There are at least five welldefined proteins which inhibit plasmin in a purified system-namely, $\alpha_{2}$-macroglobulin, $\alpha_{1}$-antitrypsin, inter- $\alpha$-trypsin inhibitor, antithrombin III-heparin complex, and $\mathrm{C}_{1}$-esterase inhibitor. The physiological inhibitor of plasmin formed in blood, however, is a relatively recently described plasma protein called $\alpha_{2}$-antiplasmin. ${ }^{2}$ This inhibitor was independently identified by three groups ${ }^{3-5}$ and most probably also by a fourth. ${ }^{6}$ Upon activation of plasminogen in plasma the formed plasmin is first preferentially bound to $\alpha_{2}$-antiplasmin. Only upon complete activation of plasminogen (concentration in plasma approximately $1.5 \mu \mathrm{mol} / \mathrm{l}$ ), resulting in saturation of the inhibitor (concentration $1 \mu \mathrm{mol} / \mathrm{l}$ ), is the excess plasmin neutralised by $\alpha_{2}$-macroglobulin. In the presence of normal concentrations of these two inhibitors the other plasma protease inhibitors do not play a role in the inactivation of plasmin.

$\alpha_{2}$-ANTIPLASMIN (THE PHYSIOLOGICAL

PLASMIN INHIBITOR)

$\alpha_{2}$-Antiplasmin is a single chain glycoprotein with a molecular weight of 70000 containing approximately $13 \%$ carbohydrate. 4 The inhibitor is immunochemically different from the other known plasma protease inhibitors. $\alpha_{2}$-Antiplasmin forms a very stable 1:1 stoichiometric complex with plasmin, which is devoid of protease or esterase activity. 45 Complex formation occurs by strong interaction between the light-(B)-chain of plasmin and the inhibitor. The physiological role of $\alpha_{2}$-antiplasmin as an inhibitor of proteases other than plasmin seems negligible. ${ }^{8} 9$

The reaction between plasmin and $\alpha_{2}$-antiplasmin proceeds in at least two steps - a very fast reversible second order reaction followed by a slower irreversible first order reaction ${ }^{1011}$ and may be represented by

$$
\mathbf{P}+\mathbf{A} \underset{\mathrm{k}_{-1}}{\stackrel{\mathrm{k}_{1}}{\rightleftarrows}} \text { PA } \stackrel{\mathbf{k}_{2}}{\longrightarrow} \text { PA }^{\prime}
$$

The rate constant $\mathrm{k}_{1}$ at $\mathrm{pH} 7.5$ is $3.8 \times 10^{7} \mathrm{M}^{-1} \mathrm{~s}^{-1}$ and $1.8 \times 10^{7} \mathrm{M}^{-1} \mathrm{~s}^{-1}$ for the two plasmin forms which have different affinities for lysine-Sepharose. ${ }^{11}$ This reaction rate is one of the fastest so far described for protein-protein interactions and is one order of magnitude higher than the reaction rate of trypsin with its inhibitors. The dissociation constant of the reversible step is approximately $2 \times 10^{-10} \mathrm{M}$ and the rate constant of the second step $4 \times 10^{-3} \mathrm{~s}^{-1} .^{11}$ Plasmin which has 6-aminohexanoic acid ${ }^{11}$ or lysine ${ }^{10}$ bound to its lysine-binding sites or substrate bound to its active site ${ }^{11}$ reacts only very slowly with $\alpha_{2}$-antiplasmin. These findings indicate that free lysine-binding sites and a free active site in the plasmin molecule are of great importance for the rate of its reaction with $\alpha_{2}$-antiplasmin. As discussed further, these interactions are probably of great importance for the regulation of fibrinolysis in vivo.

A structural analysis of the plasmin- $\alpha_{2}$-antiplasmin complex suggested that the stable complex is formed by a plasmic attack at a specific leucylmethionyl peptide bond in the $\mathrm{COOH}$-terminal portion of the inhibitor. A strong, probably covalent bond is formed between the active site seryl residue in plasmin and the carbonyl group of this specific leucyl residue in the inhibitor. ${ }^{12}$

The turnover of ${ }^{125} I$-labelled $\alpha_{2}$-antiplasmin was studied in control subjects and in patients during thrombolytic therapy. ${ }^{13}$ In the control group $\alpha_{2}$-antiplasmin had a plasma half life of $2.64 \pm 0.32$ days and a fractional catabolic rate of $0.53 \pm 0.09$ of 
the plasma pool per day. During thrombolytic therapy the half life shortened to approximately 0.5 days as a result of formation of plasmin- $\alpha_{2}-$ antiplasmin complex. The long half life of the plasmin- $\alpha_{2}$-antiplasmin complex was confirmed by studying the turnover of the purified complex both before and during thrombolytic therapy in patients with thrombotic disease.

The normal concentration of $\alpha_{2}$-antiplasmin is ketween $80 \%$ and $120 \%$ (mean \pm 2 SD) of the value obtained for pooled normal plasma.14-16 The concentration of $\alpha_{2}$-antiplasmin in pooled normal plasma is approximately $1 \mu \mathrm{mol} / 1.457$ The concentration may decrease to below $30 \%$ in severe cases of liver disease or intravascular coagulation ${ }^{14-16}$ but is normal in patients with cardiovascular, renal, or malignant disease. The inhibitor is temporarily exhausted during thrombolytic therapy with streptokinase, ${ }^{15} 17$ when measured enzymatically. Residual antigen may, however, be found immunologically representing complexed or degraded inhibitor, or both. ${ }^{17} \alpha_{2}$-Antiplasmin is a weak acute phase reactant. ${ }^{15}$ Possibly some of the $\alpha_{2}$-antiplasmin in plasma is inactive. ${ }^{5}$

$\alpha_{2}$-ANTIPLASMIN AND REGULATION OF

FIBRINOLYSIS

Physiological fibrinolysis appears to be regulated and controlled by specific molecular interactions between plasminogen activator and fibrin, between plasminogen and fibrin, and between plasmin and $\alpha_{2}$ antiplasmin.

An important property of the blood-vasculartissue type of plasminogen activator is its high affinity for fibrin, ${ }^{1819}$ which has been used for its isolation. ${ }^{20}$ Tissue activator is a relatively poor plasminogen activator in pure systems but fibrin strikingly stimulates the activation. ${ }^{20} 21$

Human plasminogen and plasmin contain structures, known as lysine-binding sites, which are responsible for their interaction not only with amino-acids such as lysine or 6-aminohexanoic acid $^{22-24}$ but also with fibrin ${ }^{25}$ and with antiplasmin. ${ }^{47}$ In purified systems native plasminogen (with $\mathrm{NH}_{2}$-terminal glutamic acid) has a weak affinity for fibrin whereas the partially degraded form of plasminogen (with $\mathrm{NH}_{2}$-terminal lysine) has a much stronger affinity. ${ }^{26}$ When whole plasma is clotted approximately $4 \%$ of the plasminogen is specifically bound to fibrin through its lysine-binding sites. ${ }^{27}$

The rapidity of the plasmin- $\alpha_{2}$-antiplasmin reaction is strongly dependent on the availability of free lysine-binding sites and active site in the enzyme. At a concentration of $1 \mu \mathrm{mol} / \mathrm{l}$ of $\alpha_{2}$-antiplasmin (the normal plasma concentration) the half life of small amounts of free plasmin can be calculated to be about $100 \mathrm{~ms}$. Plasmin with occupied lysine-binding sites and active site, however, would react at least 100 times slower and have a half life of the order of magnitude of $10 \mathrm{s.}^{28}$

Thus fibrinolysis in vivo seems to be regulated at two levels: (1) efficient activation at the fibrin surface of fibrin-bound plasminogen by fibrin-bound plasminogen activator, and (2) degradation of fibrin by fibrin-bound plasmin which is protected from rapid inactivation by $\alpha_{2}$-antiplasmin since it has both its lysine-binding sites and active site occupied. Since the fibrin-bound plasmin has an estimated half life of about $10 \mathrm{~s}$ effective clot dissolution in vivo would also seem to require a continous replacement at the fibrin surface of inactivated plasmin molecules (complexed with $\alpha_{2}$-antiplasmin) by plasminogen molecules. ${ }^{28-29}$

Several lines of evidence indicate that this model for the regulation of fibrinolysis, which was constructed mainly on the basis of molecular interactions which were demonstrated in purified systems, is also operative in vivo. ${ }^{30}$

\section{$\alpha_{2}$-MACROGLOBULIN}

$\alpha_{2}$-Macroglobulin represents the slower reacting plasmin inhibitor of plasma. Its role seems to be to inactivate plasmin formed in excess of the inhibitory capacity of $\alpha_{2}$-antiplasmin. ${ }^{35}$ Indeed, when the plasma plasminogen (concentration approximately $1.5 \mu \mathrm{mol} / \mathrm{l})$ is activated the formed plasmin is initially primarily bound to $\alpha_{2}$-antiplasmin (concentration approximately $1 \mu \mathrm{mol} / \mathrm{l})$ until after its saturation. Excess plasmin is neutralised by $\alpha_{2}$-macroglobulin. A number of reviews on the physiology and biochemistry of $\alpha_{2}$-macroglobulin have recently appeared. ${ }^{31-33}$

OTHER PLASMA PROTEASE INHIBITORS

There are at least three plasma protease inhibitors in addition to $\alpha_{2}$-antiplasmin and $\alpha_{2}$-macroglobulin that inhibit plasmin in purified systems. These are $\alpha_{1}$-antitrypsin, antithrombin III, and C1-inactivator $^{34}$ Inter- $\alpha$-trypsin inhibitor is a polyvalent inhibitor and probably also reacts to some extent with plasmin. ${ }^{34}$ In the presence of normal concentrations of $\alpha_{2}$-antiplasmin and $\alpha_{2}$-macroglobulin, however, none of these inhibitors play a role in the neutralisation of plasmin formed in the blood. ${ }^{3}{ }^{35}$

Purified antithrombin III is a progressive, timedependent inhibitor of purified plasmin. Heparin accelerates the rate of this reaction 50 to 100 fold $^{36}$ On the basis of these findings it has been suggested that antithrombin-heparin complex may be a major inhibitor of in-vivo fibrinolysis. The role of antithrombin III-heparin complex as an inhibitor of plasmin formed in plasma has been re-evaluated 
in vitro and in vivo. ${ }^{37} 38$ In the absence of heparin and after complete activation of the plasma plasminogen about $1 \%$ of the formed plasmin binds to antithrombin III. In the presence of therapeutic concentrations of heparin (1-2 IU/ml plasma) this value increased to $2-5 \%$ both in vitro and in vivo. These data suggest that the antithrombin IIIheparin complex plays a very limited role in the inactivation of plasmin.

PLASMIN INHIBITORS FROM PLATELETS Johnson and Schneider ${ }^{39}$ reported on an antiplasmin activity of bovine platelets which accounted for a major part of the antiplasmin of bovine blood. In human blood, however, the platelets contributed only $1-3 \%$ of the antiplasmin activity. 4041 The platelet contribution to the total antiplasmin activity of whole human blood is therefore probably small.

Antiplasmin materials in platelets have, however, been characterised to some extent. McDonagh et al. ${ }^{42}$ found two antiplasmin activities, one of which was platelet factor XIII and the other one was eluted earlier on Sephadex G-200. Ganguly et al.4344 described low molecular weight antiplasmins, which were dialysable in extracts of human platelets. All these plasmin inhibitors are at present poorly characterised.

\section{Inhibitors of plasminogen activation in human blood}

The existence in blood of physiological inhibitors to the activation of plasminogen has been much disputed. The demonstration of activation inhibitors in plasma is indeed hampered by two obstacles. Firstly, it is very difficult to measure antiactivator activity in the presence of antiplasmins. Antiactivator activity may, however, be demonstrated in the following ways: complex formation between activator and antiactivator, inhibition of activatorcatalysed hydrolysis of low molecular weight substrates, and inhibition of cleavage of the internal peptide bond in plasminogen. ${ }^{45}$ Secondly, the various protease inhibitors in plasma may each have some affinity for plasminogen activators and in concert confer some inhibitory activity to the plasma without actually being specific inhibitors. Despite these difficulties it seems, however, that plasma contains components which act or may act as inhibitors of plasminogen activation. But the physiological role of most of these inhibitors is unknown.

Plasminogen activation may occur by three different pathways: an intrinsic or humoral pathway in which all participating components are present in precursor form in the blood, an extrinsic pathway in which the activator originates from tissues or from the vessel wall and is released into the blood by certain stimuli or trauma, and an exogenous pathway in which the activating substances streptokinase or urokinase may be infused for therapeutic purposes. All plasminogen activators studied so far exert their action through hydrolysis of the Arg 560-Val 561 bond in plasminogen.

Intrinsic activation of plasminogen may occur by one or more pathways involving factor XII (Hageman factor), prekallikrein (Fletcher factor), high molecular weight kininogen (Fitzgerald factor), and possibly other components. However, the exact mechanism of this activation as well as its biological role remain unknown.

The plasminogen activator found in blood represents released vascular plasminogen activator, and these activators are similar or identical to the tissue activator but different from urokinase.

The physiological importance of extrinsic plasminogen activators has been inferred from the association between low blood fibrinolytic activity and thrombotic or atherosclerotic disease.

\section{INHIBITORS OF INTRINSIC PLASMINOGEN} ACTIVATION

Several inhibitors of intrinsic plasminogen activation occur in human plasma, $\mathrm{C} \overline{1}$-inactivator, ${ }^{46}$ an inhibitor of factor XIIa-induced fibrinolysis, 4748 heparin-antithrombin III complex, ${ }^{49}$ and $\alpha_{2}$-macroglobulin. ${ }^{50}$ Since the physiological role of the intrinsic fibrinolytic pathway is not established the role of these inhibitors in the regulation and control of fibrinolysis thus remains entirely speculative.

\section{INHIBITORS OF EXTRINSIC PLASMINOGEN ACTIVATION}

The presence in plasma of inhibitors of extrinsic plasminogen activators forming a complex which dissociates in the presence of fibrin has been postulated already in the $1950 \mathrm{~s}^{19}$ and also in more recent studies. ${ }^{51}$ The formation of a reversible activator-activator inhibitor complex which dissociates in the presence of fibrin has been invoked to explain the rapid lysis of fibrin in plasma and the resistance of fibrinogen to degradation by plasmin. ${ }^{51}$ The enhancing effect of fibrin on the plasminogen activation may be explained by adsorption of activator and plasminogen to its surface facilitating activation. ${ }^{202128}$ The evidence for the existence of a specific inhibitor of extrinsic plasminogen activators in plasma, forming a reversible complex, can thus at best be regarded as preliminary. ${ }^{52}$

There is good evidence that a significant amount of extrinsic plasminogen activator released in the blood is cleared in vivo by mechanisms other than neutralisation by plasmatic inhibitors. Indeed, whereas 
plasminogen activator released in the plasma by nicotinic acid injection in normal subjects has a half life in vivo of approximately $15 \mathrm{~min}^{5354}$ its half life in plasma in vitro is approximately $75 \mathrm{~min},{ }^{53}$ as measured with clot lysis assays.

\section{INHIBITORS OF EXOGENOUS PLASMINOGEN ACTIVATION}

Human plasma contains antibodies directed against streptokinase, which most probably result from previous infections with beta-haemolytic streptococci. The amount of streptokinase antibodies varies over a wide range among individuals. Verstraete et al. ${ }^{55}$ found that 352000 units of streptokinase were required to neutralise the circulating antibodies in $95 \%$ of a healthy population, but that the individual requirements ranged between 25000 and 3000000 units. Since streptokinase reacts with antibodies and is thereby rendered biochemically inert, sufficient streptokinase must be infused to neutralise the antibodies before fibrinolytic activation is obtained.$^{56} \mathrm{~A}$ few days after streptokinase injection the antistreptokinase titre rises rapidly to 50 to 100 times the preinfusion value and remains high for 4 to 6 months, during which renewed treatment is impracticable. Administration of corticosteroids commonly is used as adjuvant to streptokinase to prevent allergic side reactions. The streptokinaseplasmin(ogen) activator complex is virtually unreactive towards $\alpha_{2}$-antiplasmin. ${ }^{57}$

The mechanism of urokinase inhibition in blood is poorly known. Urokinase-inhibitor assays based on clot lysis are strongly dependent on the presence of plasmin inhibitors and are therefore in no way specific. Assayed with clot lysis methods the half life of urokinase in vivo is 9 to $16 \mathrm{~min}$ but in vitro 27 to 61 min, ${ }^{58}$ suggesting that clearing of the enzyme from theblood plays animportant role. $\alpha_{2}$-Macroglobulin, ${ }^{59}$ $\alpha_{1}$-antitrypsin, ${ }^{60}$ antithrombin III, ${ }^{61}$ and $\alpha_{2}$-antiplasmin $^{4}$ all inhibit urokinase slowly.

INHIBITORS OF PLASMINOGEN ACTIVATION FROM PLATELETS

Platelets contain inhibitors which have been claimed primarily to inhibit fibrinolysis induced by activators. ${ }^{62-65}$ Washed platelets, at a concentration which does not inhibit plasmin, are capable of inhibiting plasminogen activators. ${ }^{63}$ Murray et al.$^{64}$ partially purified an inhibitor of urokinase and tissue activator from human platelets with an estimated molecular weight of 45000 . Moore et al. ${ }^{65}$ isolated a fraction possessing antiurokinase activity but no antiplasmin activity, in addition to a fraction containing antiplasmin activity.

The physiological significance of these inhibitors is uncertain. They may have a role in the protection of thrombi from premature lysis.
Synthetic inhibitors of fibrinolysis used for clinical application

Certain amino-acids such as 6-aminohexanoic acid (epsilon-aminocaproic acid, EACA), trans-4-aminomethylcyclohexane-1-carboxylic acid (AMCHA, tranexamic acid), and p-aminomethylbenzoic acid (PAMBA) inhibit fibrinolysis both in vitro and in vivo. ${ }^{66}$ The relation between the structure of these substances and their antifibrinolytic effect has been studied in detail.66 Their clinical usefulness has recently been reviewed. ${ }^{67}$ In purified systems, however, these agents greatly accelerate the activation of native plasminogen. ${ }^{68} 69$ This paradox has recently been elucidated. ${ }^{20} 70$

Native plasminogen (with $\mathrm{NH}_{2}$-terminal glutamic acid) is slowly activated by urokinase, whereas partially degraded plasminogen (with $\mathrm{NH}_{2}$-terminal lysine, valine, or methionine) is rapidly activated. ${ }^{68} 69$ In the presence of EACA, however, the activation rate of native plasminogen is greatly increased and approaches that of the partially degraded plasminogen. This acceleration has been ascribed to conformational changes in the plasminogen molecule induced by the presence of EACA or removal of the $\mathrm{NH}_{2}$-terminal part of the molecule. The conformational change is probably a result of the dissociation between a site in the $\mathrm{NH}_{2}$-terminal part (residues ${ }^{45-51}$ ) and a structure in the plasminogen molecule which binds the antifibrinolytic amino acids ('lysine-binding site'). ${ }^{71} 72$ The plasminogen molecule contains at least two such lysine-binding sites. ${ }^{24} 7374$

The antifibrinolytic effect of EACA and analogues appears to result from their interference with the binding of plasmin(ogen) to fibrin. ${ }^{25-27}$ When whole plasma is clotted, approximately $4 \%$ of the plasminogen is specifically bound to fibrin through its lysine-binding sites, and this interaction is abolished by EACA. ${ }^{27}$ The specific affinity between plasminogen and fibrin seems to play an important role in the activation of plasminogen with tissue activator which is also specifically adsorbed to fibrin. ${ }^{20} 75$ Indeed, fibrin markedly potentiates the activation of plasminogen, but this stimulating effect is completely lost in the presence of EACA. ${ }^{20} 70 \mathrm{EACA}$ and its more active analogue tranexamic acid have been successfully used to reduce blood loss in essential menorrhagia, prostatectomy, and dental extraction in haemophiliacs.

\section{Physiopathological conditions associated with inhibition of fibrinolysis}

A number of physiopathological changes in the blood are associated with a delayed lysis of euglobulin clots or dilute blood clots. These include 
pregnancy, hyperlipidemia, smoking, wine, and beer drinking and possibly atherosclerosis. The molecular mechanisms of inhibition of fibrinolysis by these factors is in most instances unknown.

\section{References}

${ }^{1}$ Collen D. Inhibitors of fibrinolysis. In: Kline DL, Reddy NN, eds. Fibrinolysis. CRC Press, 1979 (in press).

${ }^{2}$ Hedner U, Abildgaard U. Report on the joint meeting of the task forces on nomenclature and standards of inhibitors of coagulation and fibrinolysis. Thromb Haemostas 1978;39:524-5.

${ }^{3}$ Collen D. Identification and some properties of a new fast-reacting plasmin inhibitor in human plasma. Eur J Biochem 1976;69:209-16.

${ }^{4}$ Moroi M, Aoki N. Isolation and characterization of $\alpha_{2}$-plasmin inhibitor from human plasma. A novel proteinase inhibitor which inhibits activatorinduced clot lysis. J Biol Chem 1976;251:5956-65.

${ }^{5}$ Müllertz S, Clemmensen I. The primary inhibitor of plasmin in human plasma. Biochem $J$ 1976;159: 545-53.

${ }^{6}$ Bagge L, Björk I, Saldeen T, Wallin R. Purification and characterization of an inhibitor of plasminogen activation from post-traumatic patients. Forensic Sci 1976;7:83-6.

7 Wiman B, Collen D. Purification and characterization of human antiplasmin, the fast-acting plasmin inhibitor in plasma. Eur $J$ Biochem 1977;78:19-26.

${ }^{8}$ Edy J, Collen D. The interaction in human plasma of antiplasmin, the fast-reacting plasmin inhibitor with plasmin, thrombin, trypsin and chymotrypsin. Biochim Biophys Acta 1977;484:423-32.

${ }^{9}$ Ohlsson K, Collen D. Comparison of the reactions of neutral granulocyte proteases with the major plasma protease inhibitors and with antiplasmin. Scand $J$ Clin Lab Invest 1977;37:345-50.

${ }^{10}$ Christensen U, Clemmensen I. Kinetic properties of the primary inhibitor of plasmin from human plasma. Biochem J 1977;163:389-91.

11 Wiman B, Collen D. On the kinetics of the reaction between human antiplasmin and plasmin. Eur $J$ Biochem 1978;84:573-8.

12 Wiman B, Collen D. On the mechanism of the reaction between human $a_{2}$-antiplasmin and plasmin. $J$ Biol Chem 1979;254:9291-7.

${ }^{13}$ Collen D, Wiman B. Turnover of antiplasmin, the fast-acting plasmin inhibitor of plasma. Blood 1979; 53:313-24.

${ }^{14}$ Edy J, Collen D, Verstraete M. Quantitation of the plasma protease inhibitor antiplasmin with the chromogenic substrate S-2251. In: Davidson JF, Rowan RM, Samama MM, Desnoyers PC, eds. Progress in chemical fibrinolysis and thrombolysis, vol 3. New York: Raven Press, 1978:315-22.

${ }^{15}$ Teger-Nilsson AC, Friberger P, Gyzander E. Determination of a new rapid plasmin inhibitor in human blood by means of a plasmin specific tripeptide substrate. Scand J Clin Lab Invest 1977;37:403-9.
${ }^{16}$ Aoki N. Natural inhibitors of fibrinolysis. Progr Cardiovasc Dis 1979;21:267-86.

17 Verstraete M, Vermylen J, Schetz J. Biochemical changes noted during intermittent administration of streptokinase. Thromb Haemostas 1978;39:61-8.

${ }^{18}$ Müllertz S. A plasminogen activator in spontaneously active human blood. Proc Soc Exp Biol Med 1953; 82:291-5.

${ }^{19}$ Müllertz S. Mechanism of activation and effect of plasmin in blood. Acta Physiol Scand (Suppl) 1956; 38:130.

${ }^{20}$ Wallén P. Activation of plasminogen with urokinase and tissue activator. In: Paoletti R, Sherry S, eds. Thrombosis and urokinase. London: Academic Press, 1977:91-102.

${ }^{21}$ Camiolo SM, Thorsen S, Astrup T. Fibrinogenolysis and fibrinolysis with tissue plasminogen activator, urokinase, streptokinase-activated human globulin, and plasmin. Proc Soc Exp Biol Med 1971;138: 277-80.

${ }^{22}$ Alkjaersig $\mathrm{N}$. The purification and properties of human plasminogen. Biochem J 1964;93:171-82.

${ }^{23}$ Abiko Y, Iwamoto M, Tomikawa M. Plasminogenplasmin system. V. A stoichiometric equilibrium complex of plasminogen and a synthetic inhibitor. Biochim Biophys Acta 1969;185:424-31.

${ }^{24}$ Iwamoto M. Plasminogen-plasmin system. IX. Specific binding of tranexamic acid to plasmin. Thromb Diathes Haemorrh 1975;33:573-85.

${ }^{25}$ Wiman B, Wallén P. The specific interaction between plasminogen and fibrin. A physiological role of the lysine binding site in plasminogen. Thromb Res 1977; 10:213-22.

${ }^{26}$ Thorsen S. Differences in the binding to fibrin of native plasminogen and plasminogen modified by proteolytic degradation. Influence of omega-aminocarboxylic acids. Biochim Biophys Acta 1975;393: 55-65.

${ }^{27}$ Rakoczi I, Wiman B, Collen D. On the biological significance of the specific interaction between fibrin, plasminogen, and antiplasmin. Biochim Biophys Acta 1978;540:295-300.

${ }^{28}$ Wiman B, Collen D. On the role of $a_{2}$-antiplasmin in the regulation of fibrinolysis. In: Collen $\mathrm{D}$, Wiman $\mathrm{B}$, Verstraete $\mathrm{M}$, eds. The physiological inhibitors of blood coagulation and fibrinolysis. Amsterdam: Elsevier/North Holland, 1979:177-85.

29 Wiman B, Collen D. Molecular mechanism of physiological fibrinolysis. Nature 1978;272:549-50.

${ }^{30}$ Collen $\mathrm{D}$. On the regulation and control of fibrinolysis. Thromb Haemostas 1979;42:366.

${ }^{31}$ Harpel PC. Human $a_{2}$-macroglobulin. Methods in Enzymology 1976;45:639-52.

${ }^{32}$ Laurell CB, Jeppsson JO. Protease inhibitors in plasma. In: Putnam FW, ed. The plasma proteins, 2nd ed, vol 1. New York: Academic Press, 1975 :chap 5.

${ }^{33}$ Barret AJ, Starkey PM, Munn EA. The unique nature of the interaction of $a_{2}$-macroglobulin with proteinases. In: Fritz $\mathrm{H}$, Tschesche $\mathrm{H}$, Greene LJ, Truscheit E, eds. Proteinase inhibitors (Bayer Symposia 5). Berlin: Springer, 1974:72-7.

${ }^{34}$ Steinbuch M. Les antiprotéases du plasma. Rev Franf 
Transfus $1971 ; 14: 61-82$.

${ }^{35}$ Müllertz S. Different molecular forms of plasminogen and plasmin produced by urokinase in human plasma and their relation to protease inhibitors and lysis of fibrinogen and fibrin. Biochem $J$ 1974;143: 273-83.

${ }^{36}$ Highsmith RF, Rosenberg RD. The inhibition of human plasmin by human antithrombin-heparin cofactor. J Biol Chem 1974;249:4335-8.

${ }^{37}$ Semeraro N, Colucci M, Telesforo P, Collen D. The inhibition of plasmin by antithrombin-heparin complex. I. In human plasma in vitro. Br J Haematol 1978;39:91-9.

${ }^{38}$ Collen D, Semeraro N, Telesforo P, Verstraete $\mathbf{M}$. The inhibition of plasmin by antithrombin-heparin complex. II. During thrombolytic therapy in man. Br J Haematol 1978;39:101-10.

${ }^{39}$ Johnson SA, Schneider CL. The existence of antifibrinolysin activity in platelets. Science 1953;117: 229-30.

${ }^{40}$ den Ottolander GJH, Leijnse B, Cremer-Elfrink HMJ. Plasmatic and platelet anti-plasmins and anti-activators. Thromb Diathes Haemorrh 1967; 18:404-15.

${ }^{41}$ Ekert H, Friedlander I, Hardisty RM. The role of platelets in fibrinolysis. Studies on the plasminogen activator and anti-plasmin activity of platelets. Br J Haematol 1970;18:575-84.

${ }^{42}$ McDonagh J, Kiesselbach TH, Wagner RH. Factor XIII and antiplasmin activity in human platelets. Am J Physiol 1969;216:508-13.

${ }^{43}$ Ganguly P. A low molecular weight antiplasmin of human blood platelets. Clin Chim Acta 1972;39: 466-8.

${ }^{44}$ Mui PTK, James HL, Ganguly P. Isolation and properties of a low molecular weight antiplasmin of human blood platelets and serum. Br J Haematol $1975 ; 29: 627-37$.

${ }^{45}$ Müllertz S. Natural inhibitors of fibrinolysis. In: Davidson JF, Rowan RM, Samama MM, Desnoyers PC, eds. Progress in chemical fibrinolysis and thrombolysis, vol 3. New York: Raven Press, 1978: 213-37.

${ }^{46}$ Kluft C. Elimination of inhibition in euglobulin fibrinolysis by use of flufenamate: involvement of C1-inactivator. Haemostasis 1977;6:351-69.

${ }^{47}$ Hedner U. Studies on an inhibitor of plasminogen activation in human serum. Thromb Diathes Haemorrh 1973;30:414-24.

${ }^{48}$ Hedner U, Martinsson G. Inhibition of activated Hageman factor (factor XIIa) by an inhibitor of the plasminogen activation (PA-inhibitor). Thromb Res 1978;12:1015-23.

${ }^{49}$ Stead N, Kaplan AP, Rosenberg RD. Inhibition of activated factor XII by antithrombin-heparin cofactor. J Biol Chem 1976;251:6481-8.

${ }^{50}$ McConnell DJ. Inhibitors of kallikrein in human plasma. J Clin Invest 1972;51:1611-23.

${ }^{51}$ Gurewich V, Hyde E, Lipinski B. The resistance of fibrinogen and soluble fibrin monomer in blood to degradation by a potent plasminogen activator from cadaver limbs. Blood 1975;46:555-65.
52 Collen D. $a_{2}$-Antiplasmin inhibitor deficiency. Lancet 1979;1:1039-40.

${ }^{53}$ Fletcher AP, Biederman O, Moore D, Alkjaersig N, Sherry S. Abnormal plasminogen-plasmin system activity (fibrinolysis) in patients with hepatic cirrhosis: its cause and consequences. $J$ Clin Invest 1964;43:681-95.

${ }^{54}$ Tytgat G, Collen D, De Vreker R, Verstraete $M$. Investigations on the fibrinolytic system in liver cirrhosis. Acta Haematol 1968;40:265-74.

${ }^{55}$ Verstraete $M$, Vermylen $J$, Amery A, Vermylen C. Thrombolytic therapy with streptokinase using a standard dosage scheme. Br Med J 1966;1:454-6.

56 Johnson AJ, McCarty WR. The lysis of artificially induced intravascular clots in man by intravenous infusions of streptokinase. J Clin Invest 1959;38: 1627-43.

57 Cederholm-Williams SA, De Cock F, Lijnen HR, Collen D. Kinetics of the reactions between streptokinase, plasmin and $a_{2}$-antiplasmin. Eur $J$ Biochem 1979; (in press).

${ }^{58}$ Fletcher AP, Alkjaersig N, Sherry S, Genton E, Hirsh J, Bachmann F. The development of urokinase as a thrombolytic agent. Maintenance of a sustained thrombolytic state in man by its intravenous infusion. J Lab Clin Med 1965;65:713-31.

59 Ogston D, Bennett B, Herbert RJ, Douglas AS. The inhibition of urokinase by $a_{2}$-macroglobulin. Clin $S c i$ 1973;44:73-9.

${ }^{60}$ Clemmensen I, Christensen F. Inhibition of urokinase by complex formation with human alpha 1-antitrypsin. Biochim Biophys Acta 1976;429:591-9.

${ }^{61}$ Clemmensen I. Inhibition of urokinase by complex formation with human antithrombin III in absence and presence of heparin. Thromb Haemost 1978; 39:616-23.

62 Thorsen S, Brakman P, Astrup T. Influence of platelets on fibrinolysis: a critical review. In: Ambrus JL, ed. Hematologic reviews, vol 3. New York: Marcel Dekker, 1972:123-79.

${ }^{63}$ den Ottolander GJH, Leijnse B, Cremer-Elfrink HMJ. Plasmatic and thrombocytic antiplasmins and anti-activators. II. Thromb Diathes Haemorrh 1969; $21: 26-34$.

${ }^{64}$ Murray J, Crawford GPM, Ogston D, Douglas AS. Studies on an inhibitor of plasminogen activators in human platelets. Br J Haemat 1974;26:661-8.

${ }^{65}$ Moore S, Pepper DS, Cash JD. The isolation and characterization of a platelet-specific $\beta$-globulin ( $\beta$-thromboglobulin) and the detection of antiurokinase and antiplasmin released from thrombinaggregated washed human platelets. Biochim Biophys Acta 1975;379:360-9.

${ }^{66}$ Okamoto S, Oshiba S, Mihara H, Okamoto U. Synthetic inhibitors of fibrinolysis: in vitro and in vivo mode of action. Ann NY Acad Sci 1968;146: 414-29.

67 Verstraete M. Haemostatic drugs: a critical appraisal. The Hague: Nijhoff, 1977.

${ }^{68}$ Claeys H, Vermylen J. Physicochemical and proenzyme properties of $\mathrm{NH}_{2}$-terminal glutamic acid and $\mathbf{N H}_{2}$-terminal lysine human plasminogen. 
Influence of 6-aminohexanoic acid. Biochim Biophys Acta $1974 ; 342$ : 351-9.

69 Wallén P, Wiman B. On the generation of intermediate plasminogen and its significance for activation. In: Reich E, Rifkin DB, Shaw E, eds. Proteases and biological control. Cold Spring Harbor NY: Cold Spring Harbor Laboratory, 1975 :291-303.

70 Thorsen S. Human urokinase and porcine tissue plasminogen activator. Thesis. Copenhagen: Laegeforeningens Forlag, 1977.

${ }^{71}$ Sjöholm I, Wiman B, Wallén P. Studies on the conformational changes of plasminogen induced during activation to plasmin and by 6-aminohexanoic acid. Eur J Biochem 1973;39:471-9.

${ }^{72}$ Wiman B, Wallén P. Structural relationship between 'glutamic acid' and 'lysine' forms of human plasminogen and their interaction with $\mathrm{NH}_{2}$-terminal activation peptide as studied by affinity chromatography.
Eur J Biochem 1975;50:489-94.

${ }^{73}$ Sottrup-Jensen L, Claeys H, Zajdel M, Petersen TE, Magnusson S. The primary structure of human plasminogen: isolation of two lysine-binding fragments and one 'mini'-plasminogen (M.W. 38000 ) by elastase-catalyzed-specific limited proteolysis. In: Davidson JF, Rowan RM, Samama MM, Desnoyers PC, eds. Progress in chemical fibrinolysis and thrombolysis, vol 3. New York: Raven Press, 1978: 191-209.

${ }^{74}$ Markus G, DePasquale JL, Wissler FC. Quantitative determination of the binding of $\epsilon$-aminocaproic acid to native plasminogen. $J$ Biol Chem 1978;253: 727-32.

${ }^{75}$ Thorsen S, Glas-Greenwalt P, Astrup T. Differences in the binding to fibrin of urokinase and tissue plasminogen activator. Thromb Diathes Haemorrh 1972;28:65-74. 